\title{
Super-Agrobacterium ver. 4: Improving the Transformation Frequencies and Genetic Engineering Possibilities for Crop Plants
}

\author{
Satoko Nonaka ${ }^{1,2 *}$, Tatsuhiko Someya ${ }^{2}$, Yasuhiro Kadota ${ }^{3}, K_{\text {Kouji Nakamura }}^{2}$ \\ and Hiroshi Ezura ${ }^{1,2 *}$
}

\section{OPEN ACCESS}

Edited by:

Dominique Van Der Straeten,

Ghent University,

Belgium

Reviewed by:

Benoit Lacroix,

Stony Brook University,

United States

Kan Wang,

lowa State University,

United States

*Correspondence:

Satoko Nonaka

nonaka.satoko.gt@u.tsukuba.ac.jp

Hiroshi Ezura

ezura.hiroshi.fa@u.tsukuba.ac.jp

Specialty section:

This article was submitted to

Plant Physiology,

a section of the journal

Frontiers in Plant Science

Received: 24 April 2019

Accepted: 02 September 2019

Published: 07 October 2019

Citation:

Nonaka S, Someya T, Kadota Y, Nakamura K and Ezura H (2019)

Super-Agrobacterium ver. 4 :

Improving the Transformation

Frequencies and Genetic Engineering

Possibilities for Crop Plants.

Front. Plant Sci. 10:1204.

doi: 10.3389/fp/s.2019.01204
${ }_{1}^{1}$ Tsukuba Plant Innovation Research Center, Gene Research Center, University of Tsukuba, Tsukuba, Japan, ${ }^{2}$ Faculty of Life and Environmental Sciences, University of Tsukuba, Tsukuba, Japan, ${ }^{3}$ RIKEN Center for Sustainable Resource Science, Plant Immunity Group, Yokohama, Japan

Agrobacterium tumefaciens has been utilized for both transient and stable transformations of plants. These transformation methods have been used in fields such as breeding GM crops, protein production in plant cells, and the functional analysis of genes. However, some plants have significantly lower transient gene transfer and stable transformation rates, creating a technical barrier that needs to be resolved. In this study, SuperAgrobacterium was updated to ver. 4 by introducing both the ACC deaminase (acdS) and GABA transaminase ( $g a b T$ ) genes, whose resultant enzymes degrade ACC, the ethylene precursor, and GABA, respectively. A. tumefaciens strain GV2260, which is similar to other major strains (EHA105, GV3101, LBA4404, and MP90), was used in this study. The abilities of the Super-Agrobacterium ver. 4 were evaluated in Erianthus ravennae, Solanum lycopersicum "Micro-Tom," Nicotiana benthamiana, and S. torvum. Super-Agrobacterium ver. 4 showed the highest T-DNA transfer (transient transformation) frequencies in E. ravennae and S. lycopersicum, but not in $N$. benthamiana and $S$. torvum. In tomato, Super-Agrobacterium ver. 4 increased the stable transformation rate by 3.6-fold compared to the original GV2260 strain. Super-Agrobacterium ver. 4 enables reduction of the amount of time and labor required for transformations by approximately $72 \%$, and is therefore a more effective and powerful tool for plant genetic engineering and functional analysis, than the previously developed strains. As our system has a plasmid containing the acdS and gabT genes, it could be used in combination with other major strains such as EHA105, EHA101, LBA4404, MP90, and AGL1. Super-Agrobacterium ver. 4 , could thus possibly be a breakthrough application for improving basic plant science research methods.

Keywords: Agrobacterium tumefaciens, Super-Agrobacterium, genetic engineering, plant transformation, gamma-aminobutyric acid, ethylene, GABA transaminase, ACC deaminase 


\section{INTRODUCTION}

Agrobacterium tumefaciens is an a-proteobacteria that causes crown gall disease in many agriculturally and economically important species, such as those from the families Rosaceae (rose, apple, cherry, and pear), Vitaceae (grape), and the genus Juglans (walnut) (Kado, 2014). A. tumefaciens has the ability to transfer T-DNA from bacterial cells to plant cells (T-DNA transfer). Transferred T-DNA is integrated into the plant genome via complicated plant cell systems (Guo et al., 2019), and results in crown gall disease. To utilize this unique ability of $A$. tumefaciens for research purposes, there has been a great deal of effort to remove its oncogenesis characteristics, and to develop a binary vector system (Zambryski et al., 1983; Hoekema et al., 1983; Bevan, 1984; Komari et al., 2006). There has been further effort to increase the T-DNA transfer frequency of $A$. tumefaciens; one effective strategy was to upregulate its vir gene expression levels. The application of vir gene inducers (Stachel et al., 1985; Stachel et al., 1986; Cangelosi et al., 1990; He et al., 2009; Hu et al., 2013), using ternary system (van der Fits et al., 2000), utilization of Super-binary vectors (Komari, 1990; Hiei et al., 1994; Ishida et al., 1996), and a modification of the Ori of the binary vector (Ye et al., 2011; Vaghchhipawala et al., 2018), have subsequently improved its transformation frequencies.

Another strategy to increase T-DNA transfer frequencies was the removal of the negative factors of the Agrobacteriumplant interactions, such as ethylene, the gaseous phytohormone. Applications, such as aminoethoxyvinylglycine (AVG), an ethylene biosynthesis inhibitor, and $\mathrm{AgNO}_{3}$ or silver thiosulfate (STS), ethylene perception inhibitors, were effective at improving the T-DNA transfer frequencies in tomato, melon, and bottle gourd (Davis et al., 1992; Ezura et al., 2000; Han et al., 2005; Nonaka and Ezura, 2014). An alternative strategy was the utilization of ACC deaminase (AcdS) activity, which cleaves ACC, the ethylene precursor, to ammonia and a keto-butyrate. This enzyme was found in some plant growth promoting bacteria (PGPBs), such as Pseudomonas sp., which were found on the plant surface (Sheehy et al., 1991), and these bacteria utilize ACC as a nitrogen source. However, A. tumefaciens C58 strain, which was the original strain for Agrobacterium-mediated transformation, does not have the acdS gene or its activities (Wood et al., 2001; Nonaka et al., 2008a). Therefore, the utilization AcdS activity seemed to be reasonable. Indeed, A. tumefaciens GV2260 that had AcdS activity introduced into it, was efficacious in the suppression of ethylene evolution from plant tissues during co-cultivation and increasing T-DNA transfer [Nonaka et al., 2008a (SuperAgrobacterium ver.1); Ntui et al., 2010; Hao et al., 2010]. Moreover, Super-Agrobacterium ver.1 showed stronger inhibition of ethylene evolution and higher T-DNA transfer frequencies than chemical treatments in melon and wild water melon (Nonaka et al., 2008a; Malambane et al., 2018). For the further improvement of SuperAgrobacterium ver.1, a stronger promoter was used to drive acdS. In Super-Agrobacterium ver.1, the expression of acdS gene was under the control of the lac promoter, which shows constitutive expression in A. tumefaciens. Instead of the lac promoter, the virD promoter was cloned from $A$. tumefaciens and was used in SuperAgrobacterium ver. 2 (Someya et al., 2013). virD genes are induced by acetosyringone at $\mathrm{pH} 5.2$, which is the co-cultivation condition.
This promoter showed higher gene expression levels than the lac promoter during co-cultivation (Someya et al., 2013), resulting in higher T-DNA transfer frequencies in Super-Agrobacterium ver. 2 than in ver.1 (Someya et al., 2013).

Gamma-aminobutyric acid (GABA), an amino acid, was determined to be another negative factor in Agrobacteriumplant interactions (Chevrot et al., 2006; Haudecoeur et al., 2009; Nonaka et al., 2017). GABA is taken up into A. tumefaciens and triggers the degradation of the quorum-sensing (QS) signal, resulting in the reduced horizontal gene transfer of the Ti plasmid and the aggressiveness of the plant host (Chevrot et al., 2006; Haudecoeur et al., 2009). GABA is a biologically active agent in animals, plants, and bacteria. In animals, GABA is particularly well known as an effector, lowering blood pressure (Elliott and Hobbiger, 1959; Takahashi et al., 1961; Takahashi et al., 1995), and its mechanism of action has been well studied. It was found that some chemical compounds control GABA effect in animals. While contrarily, in plants, GABA was know as modulator cell elongation, abiotic stress and pathogen attack (Park et al., 2010; Renault et al., 2011; Shelp et al., 2012; Forlani et al., 2014), but the action mechanisms of GABA in-plants are still to be clarified, and the chemical compounds related with GABA perception or signal transduction in plants have not been identified. Some bacteria are known to harbor GABA transaminase ( $g a b T$ ), a GABA degradation enzyme. Utilization of GabT activities increased the transient and stable transformation frequencies in tomato and grass plants [Nonaka et al., 2017 (Super-Agrobacterium ver.3)]. Super-Agrobacterium ver. 3 was also effective in the agroinfiltration method (Hoshikawa et al., 2019; Knoch et al., 2019).

Stable transformation techniques are important as they are used for breeding GM crops. Transient transformations are also widely used in plant science; for example, protein production by excessive gene overexpression and gene function analysis by the virus-induced gene silencing (VIGS) system (Velásquez et al., 2009), are based on transient gene transfers. However, some plants have significantly lower transient gene transfer rates, creating a limitation in plant science research that should be resolved by increasing the transient transformation (T-DNA transfer) frequency in a wide variety of plant hosts. Therefore, the host range of $A$. tumefaciens must be enlarged, and its transformation efficiency increased. In this study, to further increase the transient and/or stable transformation frequencies, Super-Agrobacterium was updated to ver. 4 by introducing both AcdS and GabT activity to the GV2260 strain, which has similar abilities, compared with other strains such as EHA105, EHA101, LBA4404, and MP90 (Sun et al., 2006 and Chetty et al., 2013). The abilities of the Super-Agrobacterium ver. 4 were evaluated in Erianthus ravennae, Solanum lycopersicum "Micro-Tom," Nicotiana benthamiana, and S. torvum for both transient and stable transformations.

\section{MATERIALS AND METHODS}

\section{Bacterial Strains, Vectors, and Culture Conditions}

All bacterial strains and vectors, which were used in this study, were listed up in Table 1. The vector maps were described in 
TABLE 1 | List of $A$. tumefaciens strains and plasmids that are used in this study.

\begin{tabular}{|c|c|c|}
\hline & Description & Reference \\
\hline \multicolumn{3}{|l|}{ Strain name } \\
\hline GV2260 & Non-oncogenic $A$. tumefaciens strain & Deblaere et al. (1985) \\
\hline C & A. tumefaciens GV2260 (pBBR1MCS-5) & Nonaka et al. (2008a) \\
\hline V1 & A. tumefaciens GV2260 (pBBRacdS) (Super-Agrobacterium ver. 1) & Nonaka et al. (2008a) \\
\hline V3 & A. tumefaciens GV2260 (pBBRgabT) (Super-Agrobacterium ver. 3) & Nonaka et al. (2017) \\
\hline V4 & A. tumefaciens GV2260 (pBBRacdSgabT) (Super-Agrobacterium ver. 4) & This study. \\
\hline C-E & A. tumefaciens GV2260 (pBBR1MCS-5, pEKH $\left.{ }_{2}\right)$ & Nonaka et al. (2008a) \\
\hline V1-E & A. tumefaciens GV2260 (pBBRacdS, pEKH ${ }_{2}$ ) (Super-Agrobacterium ver. 1) & Nonaka et al. (2008a) \\
\hline V3-E & A. tumefaciens GV2260 (pBBRgabT, pEKH ${ }_{2}$ ) (Super-Agrobacterium ver. 3) & Nonaka et al. (2017) \\
\hline V4-E & A. tumefaciens GV2260 (pBBRacdSgabT, pEKH ${ }_{2}$ ) (Super-Agrobacterium ver. 4) & This study. \\
\hline C-G & A. tumefaciens GV2260 (pBBR1MCS-5, plG121-Hm) & Nonaka et al. (2008a) \\
\hline V1-G & A. tumefaciens GV2260 (pBBRacdS, plG121-Hm) (Super-Agrobacterium ver. 1) & Nonaka et al. (2008a) \\
\hline V3-G & A. tumefaciens GV2260 (pBBRgabT, plG121-Hm) (Super-Agrobacterium ver. 3) & Nonaka et al. (2017) \\
\hline V4-G & A. tumefaciens GV2260 (pBBRacdSgabT, plG121-Hm) (Super-Agrobacterium ver. 4). & This study. \\
\hline C-Q & A. tumefaciens GV2260 (pBBR1MCS-5, pEAQ-GFP-HT) & Nonaka et al. (2008a) \\
\hline V1-Q & A. tumefaciens GV2260 (pBBRacdS, pEAQ-GFP-HT) (Super-Agrobacterium ver. 1) & Nonaka et al. (2008a) \\
\hline V3-Q & A. tumefaciens GV2260 (pBBRgabT, pEAQ-GFP-HT) (Super-Agrobacterium ver. 3), & Nonaka et al. (2017) \\
\hline V4-Q & A. tumefaciens GV2260 (pBBRacdSgabT, pEAQ-GFP-HT) (Super-Agrobacterium ver. 4), & This study. \\
\hline \multicolumn{3}{|l|}{ Plasmid } \\
\hline pBBR1MCS-5 & Broad-host-range shuttle vector; Gen ${ }^{R}$ & Kovach et al. (1995) \\
\hline pBBRacdS & Overexpression vector for ACC deaminase under the control of the lac promoter; $\mathrm{Gm}^{\mathrm{R}}$ & Nonaka et al. (2008a) \\
\hline pBBRgabT & Overexpression vector for GABA under the control of the lac promoter; $\mathrm{Gm}^{\mathrm{R}}$ & Nonaka et al. (2017) \\
\hline pBBRacdSgabT & Overexpression vector for ACC deaminase and GABA transaminase under the control of the lac promoter; $\mathrm{Gm}^{\mathrm{R}}$ & This study. \\
\hline $\mathrm{pEKH} \mathrm{K}_{2}$ & $\begin{array}{l}\text { pEKH2-nosPNPTII-ubiPGUS-35SPHPT, bBinary vector plasmid carrying the b-glucuronidase gene (uidA) between the } \\
\text { T-borders; Sp }\end{array}$ & $\begin{array}{l}\text { Hoshikawa et al. } \\
\text { (2012) }\end{array}$ \\
\hline plG121-Hm & Binary vector plasmid carrying the b-glucuronidase gene (uidA) between the T-borders; $\mathrm{Km}^{\mathrm{R}}$ & Ohta et al. (1990) \\
\hline pEAQ-GFP-HT & Binary vector plasmid carrying the Green Fluorescent Protein gene (GFP) between the T-borders; $\mathrm{Km}^{\mathrm{R}}$ & Sainsbury et al. (2009) \\
\hline
\end{tabular}

Supplemental Figure 1. A. tumefaciens strains were grown at $28^{\circ} \mathrm{C}$ in Luria Broth (LB) medium (1\% bacto-tryptone, $0.5 \%$ yeast extract, and $0.5 \% \mathrm{NaCl}$ ). Antibiotics were added at the following final concentrations: ampicillin at $100 \mu \mathrm{g} /$ $\mathrm{ml}$, gentamicin at $50 \mu \mathrm{g} / \mathrm{ml}$, spectinomycin at $50 \mu \mathrm{g} / \mathrm{ml}$, and kanamycin at $50 \mu \mathrm{g} / \mathrm{ml}$. A. tumefaciens strains were then cultured on solid LB medium at $28^{\circ} \mathrm{C}$ for 2 days. A single colony was picked and cultured in $2 \mathrm{ml}$ of $\mathrm{LB}$ medium at $28^{\circ} \mathrm{C}$ and $200 \mathrm{rpm}$ for 2 days until the pre-culture reached the stationary phase. From this, $15 \mu \mathrm{l}$ of culture was harvested and added to $15 \mathrm{ml}$ of LB medium and cultured at $28^{\circ} \mathrm{C}$ and $200 \mathrm{rpm}$. When the O.D. ${ }_{600}$ of the culture reached 0.7 to 0.9 , the cells were then centrifuged, collected, and checked for enzymatic activity. For transformations, the pelleted bacterial cells were resuspended in liquid Murashige and Skoog (1962) (MS) containing $30 \mathrm{~g} / \mathrm{l}$ glucose, and $500 \mu \mathrm{M}$ acetosyringone at $\mathrm{pH}$ 5.2. The cell density was then adjusted to $0.4-0.5$ at O.D. ${ }_{600}$.

\section{Construction of acdS and gabT Expression Plasmids}

The gabT gene was cloned from pBBRgabT in a previous study (Nonaka et al., 2017) by polymerase chain reaction (PCR) with the primers acdSF (5'- TCTGCGCGTAATCT GCTGCTTGAGCGCAACGCAATTAATG - $3^{\prime}$ ) and gabTR (5' - CGATTCTGGACTACTGCTTCGCCTCATCAAAAC-3'). The transcription terminal sequence of the ampicillin resistance gene was cloned from the pUC18 vector using PCR with the primer's amp_ter-for2 (5'-GCTAGAATTCCTGTCAGACCA
AGTTTACTC-3') and amp_ter-rev2 (5'-CATTAATTG CGTTGCGCTCAAGCAGCAGATTACGCGCAGA-3'). Then, the two fragments were combined by fusion-PCR with the primer's amp_ter-for 2 and gabTR. The ligated fragment was inserted into pBBRacdS (Nonaka et al., 2008a) and digested with EcoRI and XbaI (New England Biolabs, Hirchin, UK). The expression of both genes was under the control of the lac $Z$ gene promoters (pBBRacdSgabT, Figure 1A). pBBR1MCS5, pBBRacdS, pBBRgabT, and pBBRacdSgabT were introduced into A. tumefaciens GV2260 ( $\mathrm{pEKH}_{2}$-nosPNPTII-ubiPGUS35SPHPT; $\mathrm{pEKH}_{2}$ ), A. tumefaciens GV2260 (pIG121-Hm), or A. tumefaciens GV2260 (pEAQ-GFP-HT) via electroporation.

\section{ACC Deaminase Activity Assay}

Cells were collected and washed twice with $100 \mathrm{mM}$ Tris- $\mathrm{HCl}$ ( $\mathrm{pH} 8.5)$ and resuspended in $1.5 \mathrm{ml}$ of lysate buffer. The cells were lysed on ice by sonication and centrifuged at 5,000 $\times g$ at $4^{\circ} \mathrm{C}$ for $15 \mathrm{~min}$. The AcdS activity was measured according to a modified protocol based on that of Honma and Shimomura (1978). The AcdS activity was measured spectrophotometrically at $340 \mathrm{~nm}$. The protein content of the extracts was determined using the Bradford method (Bradford, 1976).

\section{GABA Transaminase Activity in A. tumefaciens}

The pellet of $A$. tumefaciens was re-suspended in $100 \mu \mathrm{l}$ of BugBuster Master mix (Novagen, MA, USA) for lysate 


\section{A}

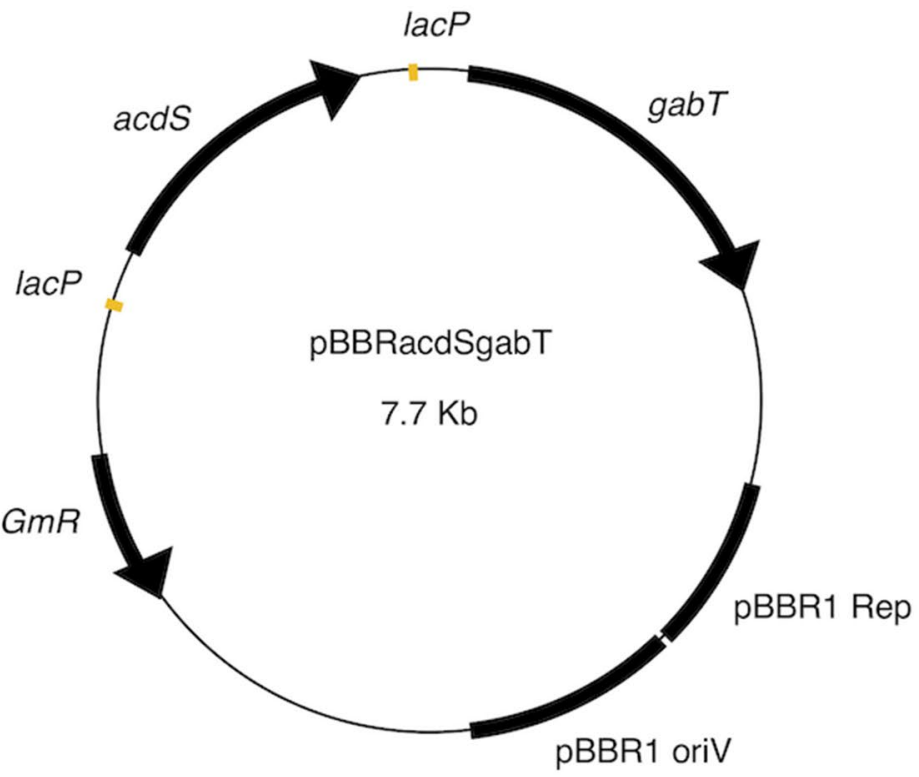

B

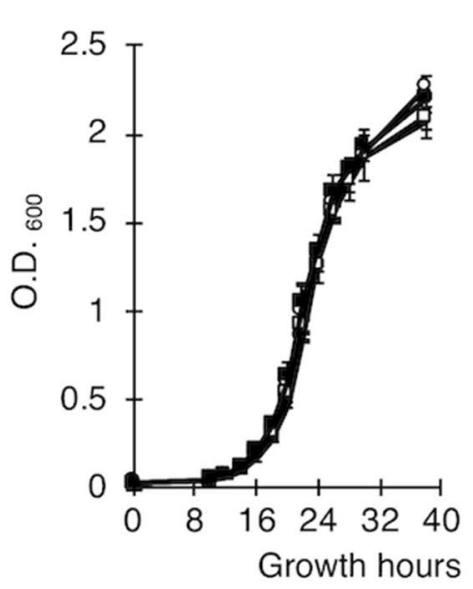

C

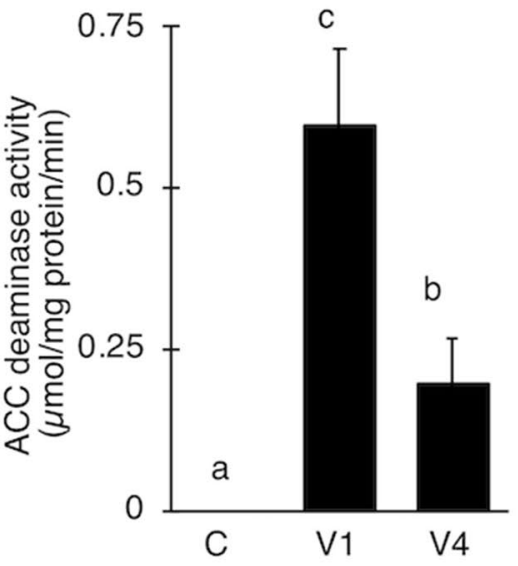

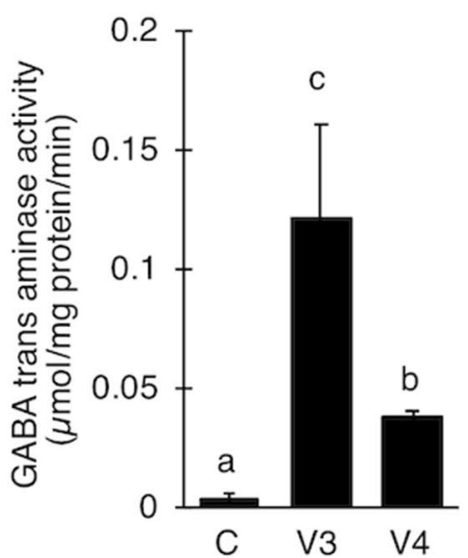

FIGURE 1 | Effect of ACC deaminase and GABA transaminase activity on the transfer of T-DNA. (A) Map of a plasmid for the expression of ACC deaminase (acdS) and GABA transaminase (gabT) in A. tumefaciens. lacP, lac gene promoter from E. coli; acdS, ACC deaminase gene from Psedomonas sp (Sheehy et al., 1991, Accession No. M73488); gabT, GABA transaminase gene from E. coli (Accession No. CP040667); pBBR1 Rep, replication protein for the broad-host-range plasmid pBBR1 from Bordetella bronchiseptica; pBBR1 oriV, replication origin of the broad-host-range plasmid pBBR1 from B. bronchiseptica; pBBR1 Rep, protein for replication required by pBBR1 oriV, GmR, Gentamicin resistance gene. (B) Growth curve of $A$. tumefaciens. Open and solid circles represent $A$. tumefaciens $C$ and V1, respectively. Open and solid squares represent $\mathrm{V} 3$ and $\mathrm{V} 4$, respectively. (C) ACC deaminase activity in $A$. tumefaciens. (D) Detection of GABA transaminase activity in A. tumefaciens. C, GV2260 (pBBRMCS1-5); V1, A. tumefaciens GV2260 (pBBRacdS); V3, A. tumefaciens GV2260 (pBBRgabT); V4, A. tumefaciens GV2260 (pBBRacdSgabT). Bars represent the standard deviation $(n=3)$. Different characters indicate values that were statistically different in the one-way ANOVA and Tukey-Kramer method, multiple comparison method $(P<0.01)$.

preparation. The protein concentration of the lysate was measured with a BCA Protein Assay Kit (Novagen, MA, USA). The amount of protein was adjusted to $100 \mu \mathrm{g}$ per reaction mixture. The reaction mixture contained $0.1 \mathrm{M}$ bicine- $\mathrm{NaOH}$,
$0.1 \mathrm{M}$ pyridoxal phosphate, $10 \mathrm{mM}$ 2-ketoglutarate, $10 \mathrm{mM}$ GABA, and a proteinase inhibitor cocktail. The reaction mixture was incubated at $37^{\circ} \mathrm{C}$. GabT metabolizes GABA to glutamate; therefore, to estimate the GabT activity, we detected the glutamate 
concentration in the reaction mixture using a Yamaki glutamate assay kit (Yamaki, Tokyo, Japan) (Akihiro et al., 2008).

\section{T-DNA Transfer Assay in E. ravennae and S. lycopersicum}

Calli of E. ravennae were kindly provided by Prof. Masahiro Mii from Chiba University, Japan. The calli were induced directly from the seeds on MS medium, containing $1 \mathrm{~g} / \mathrm{l}$ casamino acids, $2 \mathrm{mg} / \mathrm{l}$ 2,4-dichlorophenoxyacetic acid (2,4-D), $0.2 \mathrm{mg} / \mathrm{l}$ 6-benzylaminopurine (BAP), 30 g/l 4-O-a-D-glycopyranosyl-Dglycopyranose (maltose H) (Wako, Tokyo, Japan), and 3\% Gelrite (Wako, Tokyo, Japan), were subcultured for 2 weeks before inoculation. After co-cultivation, the $\beta$-glucuronidase (GUS) activity of the E. ravennae calli were assayed histochemical with X-Gluc buffer containing $100 \mathrm{mM}$ phosphate buffer, $10 \mathrm{mM}$ EDTA, $2.5 \mathrm{mM}$ potassium ferricyanide, $2.5 \mathrm{mM}$ potassium ferrocyanide, $0.1 \%$ Triton X-100, and $0.5 \mathrm{mg} / \mathrm{l} \mathrm{X}$-glucuronide. The GUS-stained calli were observed using a stereoscopic microscope (Leica: MX FLIII, DFC300 FX, Application Suite, Leica, Germany), the number of GUS-stained spots per $1 \mathrm{~g}$ of calli calculated, and the T-DNA transfer efficiency was estimated, based on the relative number of GUS spots.

Tomato seeds were washed with $70 \%$ ethanol for $10 \mathrm{~s}$, sterilized with 5\% hypochlorous acid containing 10\% Triton X-100 for $45 \mathrm{~min}$, and washed three times with sterilized water. After the third wash, the seeds were kept in water for 2 days. The sterilized tomato seeds were sown on MS medium, containing $15 \mathrm{~g} / \mathrm{L}$ sucrose (Wako, Tokyo, Japan) and 0.3\% Gelrite (Wako, Tokyo, Japan). Cotyledons from 7-day-old tomato seedlings were cut into four pieces and used to generate two locations for inoculations with $A$. tumefaciens. Thirty explants were subjected to each treatment. The inoculated explants were cultured on co-cultivation medium ( $\mathrm{pH}$ 5.2) containing MS salts, $30 \mathrm{~g} / \mathrm{L}$ glucose, $500 \mu \mathrm{M}$ acetosyringone, and $0.3 \%$ Gelrite (Wako, Tokyo, Japan) at $25^{\circ} \mathrm{C}$, for 3 days in the dark. After 3 days of co-cultivation, the tomato explants were assayed histochemically for GUS activity with X-Gluc buffer, described above. GUS stained tomato cotyledon explants were observed and images were taken using a stereoscopic microscope system (Leica: MX FLIII, DFC300 FX, Application Suite, Leica, Wetzlar, Germany). The GUS stained areas were converted into numerical values by Image J (National Institutes of Health: http://rsbweb.nih.gov/ $\mathrm{ij} /$ ) and the percentage of GUS stained area for each explant was calculated. According to the results, GUS stained tomato explants were categorized into 4 classes: (Class 1) less than $5 \%$, (Class 2) 5-10\%, (Class 3) 10-20\%, and (Class 4) more than $20 \%$. To estimate the T-DNA transfer, the frequency of more than $20 \%$ was calculated.

\section{Tomato Stable Transformation}

Tomato transformations followed the protocol by Sun et al. (2006). In brief, after 3 days of co-cultivation, tomato cotyledon segments were placed on a callus-induction medium [MS medium containing $0.3 \%$ Gelrite (Wako, Tokyo, Japan), $1.5 \mathrm{mg} / \mathrm{l}$ zeatin, $100 \mathrm{mg} / \mathrm{l}$ kanamycin, and $375 \mathrm{mg} / \mathrm{l}$ Augmentin
(GlaxoSmithKline, London, UK)] for 4 weeks. Calli that formed segments were cultured on shoot-induction medium [MS medium containing 0.3\% Gelrite (Wako, Tokyo, Japan), $1.0 \mathrm{mg} / \mathrm{l}$ zeatin, $100 \mathrm{mg} / \mathrm{l}$ kanamycin, and $375 \mathrm{mg} / \mathrm{l}$ Augmentin (GlaxoSmithKline, London, UK)] for 4 weeks. The shoots were then placed on rooting medium, which consisted of half-strength MS medium, 0.3\% Gelrite (Wako, Tokyo, Japan), $100 \mathrm{mg} / \mathrm{L}$ kanamycin, and $375 \mathrm{mg} / \mathrm{l}$ Augmentin, for 2 weeks. Tissues were each subcultured for 10-14 days.

\section{Agro Infiltration Method}

A. tumefaciens GV2260 carrying pEAQ-GFP-HT (Sainsbury et al., 2009) was grown in LB media, resuspended in $10 \mathrm{mM}$ $\mathrm{MgCl}_{2}, 10 \mathrm{mM}$ MES, pH 5.6, $150 \mu \mathrm{M}$ acetosyringone, and incubated for $3 \mathrm{~h}$ at room temperature. The leaves were then syringe infiltrated with the A. tumefaciens. Concentrations of A. tumefaciens were 0.3 at O.D. ${ }_{600}$ for N. benthamiana and 1 at O.D. ${ }_{600}$ for S. torvum. GFP fluorescence was detected 3 and 5 days after infiltration for $N$. benthamiana and $S$. torvum, respectively. Each experiment was repeated three times.

\section{Ploidy Analysis}

The ploidy of the rooting shoots was checked with flow cytometry. One square centimeter of leaf was cut from the rooting shoots, chopped, and added to $250 \mu \mathrm{l}$ of nucleus-extraction solution (CyStain UV Precise P, Sysmex, Hyogo, Japan). To purify the nucleus-extraction solution, $1 \mathrm{~mm}^{2}$ mesh was used. After purification, $1 \mathrm{ml}$ of staining solution (CyStain UV Precise P, Sysmex, Hyogo, Japan) was added and incubated for $1 \mathrm{~min}$. This solution was applied to an Attune focusing analyzer (ABI, CA, USA), and $2 \mathrm{n}$ plants were selected. The $2 \mathrm{n}$ plants were then planted on solid medium and acclimatized.

\section{Southern Blot Analysis}

Genomic DNA was extracted from young tomato leaves using Maxwell 16 System DNA Purification kits (Promega, WI, USA). The purified DNA was digested with HindIII, electrophoretically separated in $0.8 \%$ agarose gel, and transferred onto Gene Screen Plus nylon membranes (Roche Diagnostics, Basel, Swiss) with 20× saline-sodium citrate (SSC) buffer. After ultraviolet (UV) crosslinking, the membranes were hybridized in a solution containing $7 \%$ sodium dodecyl sulfate (SDS), $50 \%$ deionized formamide, $50 \mathrm{mM}$ sodium phosphate ( $\mathrm{pH} 7.0$ ), $2 \%$ blocking solution, $0.1 \%$ $\mathrm{N}$-lauroylsarcosine, $0.75 \mathrm{M} \mathrm{NaCl}$, and $75 \mathrm{mM}$ sodium citrate at $42^{\circ} \mathrm{C}$ overnight. For hybridization, a digoxigenin (DIG)-labeled DNA probe, specific for $n p t I I(0.8 \mathrm{~Kb})$, was used. A DIG-labeled probe was generated by DIG-High Prime, and the DIG signal was detected according to the manufacturer's protocol (Roche Diagnostics, Basel, Swiss).

\section{Statistical Analysis}

The average values were obtained from three biological replicates. One-way analysis of variance (ANOVA) and Tukey Kramer's multiple range test, with $P<0.01$ or $P<0.05$, were carried out 
to determine the significant differences. Statistical analyses were carried out using the SAS statistics program (version 8.0, SAS Institute Cary, NC, USA).

\section{RESULTS}

\section{Introduction of AcdS and GabT Activity Did Not Affect Bacterial Growth}

Since ethylene and GABA suppress the transfer of T-DNA in different ways, we predicted that the introduction of AcdS and GabT activity into A. tumefaciens would be effective at increasing the T-DNA transfer. These two genes were introduced by pBBR1MCS-5, the broad host range plasmid (Kovach et al., 1995) (Figure 1A, pBBRacdSgabT), and expressed under the control of the lac promoter (Nonaka et al., 2008a; Nonaka et al., 2017). To estimate whether these two genes affect bacterial growth or not, growth curves were compared for the four strains [(C), (V1), (V3), and (V4)]. In all strains, the accelerated growth period began $10 \mathrm{~h}$ after culturing, and after 18 to $26 \mathrm{~h}$, the logarithmic growth phases were observed (Figure 1B). These results indicate that introducing the acdS and gabT at the same time in $A$. tumefaciens did not affect its bacterial growth. To measure the AcdS and GabT activity, cells were collected by centrifugation, and the lysate was prepared. Then, the AcdS and GabT activity were measured, as described in previous studies (Nonaka et al., 2008a; Nonaka et al., 2017). Both activities were detected in the V4 strain, but the AcdS and GabT activities in V4 were one-third of the $\mathrm{V} 1$ and $\mathrm{V} 3$, respectively (Figures 1C, D).

\section{Evaluation of the Super-Agrobacterium for T-DNA Transfer in Plants}

To examine whether the AcdS and GabT activities were enough to increase the transfer of T-DNA, the T-DNA transfers in E. ravennae and S. lycopersicum "Micro-Tom" were observed. E. ravennae is known for its high bio-mass production and is relevant for practical agriculture. After 3 days of co-cultivation, the number of blue spots were counted to evaluate the T-DNA transfer in E. ravennae. Four strains, (C-E), (V1-E), (V3-E), and (V4-E) were used for the transformation. The V1-E, V3-E, and V4-E showed higher T-DNA transfer frequencies than the control, C-E. The inoculation of V4-E increased the T-DNA transfer frequency by 7.2, 2.4, and 1.7 times, compared to the C-E, V1-E, and V3-E, respectively (Figure 2A). Next, we evaluated the abilities of Super-Agrobacterium V4 using S. lycopersicum "Micro-Tom." Almost 100 explants of "Micro-Tom" were inoculated for each bacterial strain [(C-G), (V1-G), (V3-G), and (V4-G)]. The uidA gene was used as an indicator of T-DNA transfer, and the blue area indicated transformed cells (Figure 2B). The GUS-stained area was determined in each of the explants with Image J, as described in the Materials and Methods section (in "2.5 T-DNA transfer assay in E. ravennae and S. lycopersicum"). The degree of staining was categorized into 4 classes (Figure 2B). To evaluate the ability of the T-DNA transfer in C-G, V1-G, V3-G, and V4-G, the frequency of class 4 was compared. V4-G showed the highest frequency of class 4 ; the frequencies were 3.9, 1.4, and 1.5 times higher than the C-G, V1-G, and V3-G, respectively. V1-G

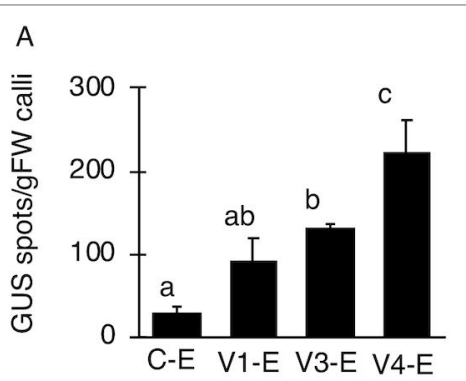

B

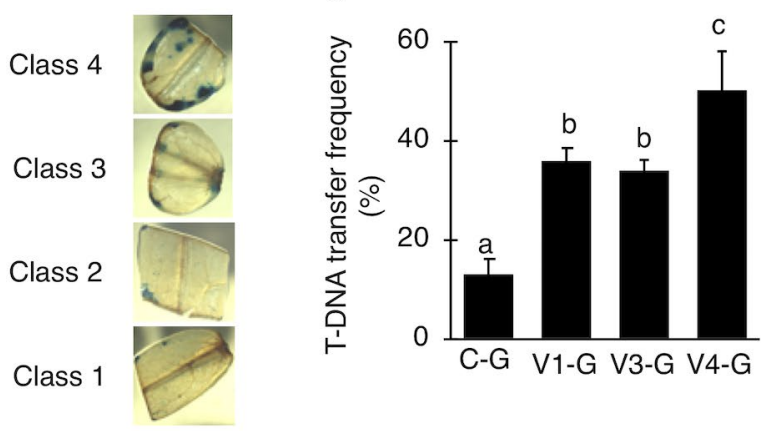

D
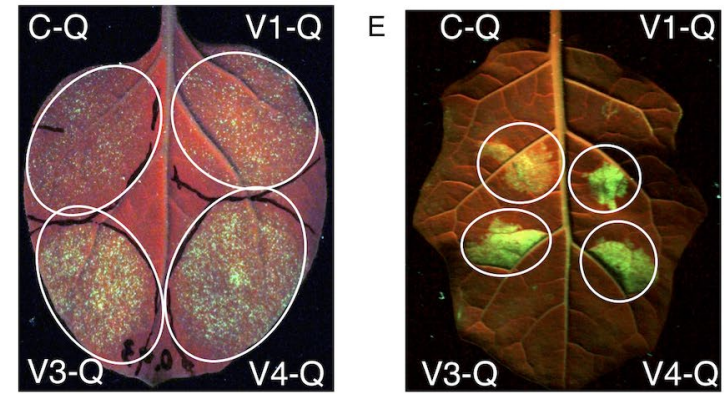

FIGURE 2 | Transient transformations in tomato via tissue culture and co-cultivation method. (A) Occurrence of T-DNA transformations in E. ravennae. The number of GUS-stained spots per $1 \mathrm{~g}$ of $E$. ravennae calli were counted for each treatment. The bars indicate the standard deviation $(n=3)$. Different characters indicate values that were significantly different according to the one-way analysis of variance, multiple comparison method $(P<0.01)$. C-E: $A$. tumefaciens GV2260 (pBBR1MCS-5, pEKH ${ }_{2}$ ), V1-E: A. tumefaciens GV2260 (pBBRacdS. pEKH ${ }_{2}$ ), V3-E: A. tumefaciens GV2260 (pBBRgabT, pEKH $\mathrm{K}_{2}$ ), V4-E: A. tumefaciens GV2260 (pBBRacdSgabT, pEKH $_{2}$ ). (B) GUS stained explants of S. Iycopersicum "Micro-Tom." Explants were prepared from 7 days old seedlings. After 3 days of co-cultivation, explants were stained. Classification of GUS-stained cotyledon explants. GUS stained tomato cotyledons were categorized depending on the stained area. Categorized into 4 classes: (Class 1) less than $5 \%$, (Class 2) 5-10\%, (Class 3) 10-20\%, and (Class 4) more than 20\%. (C) Appearance ratio Class 4 in tomato cotyledons. C-G: A. tumefaciens GV2260 (pBBRMCS1-5, plG121-Hm); V1-G: A. tumefaciens GV2260 (pBBRacdS, plG121-Hm); V3-G: A. tumefaciens GV2260 (pBBRgabT, plG121-Hm); V4-G: A. tumefaciens GV2260 (pBBRacdSgabT, plG121-Hm). Bars represent the standard deviation $(\mathrm{n}=3)$. Different characters indicate values that were statistically different in a one-way ANOVA and the Tukey-Kramer method, multiple comparison method $(P<0.01)$. (D) Transient transformation via agroinfiltration methods on $N$. benthamiana. (E) Transient transformation via Agroinfiltration methods on S. torvum. GFP signals were used as indicators of transformation. C-Q: A. tumefaciens GV2260 (pBBRMCS1-5, pEAQ-GFP-HT); V1-Q: A. tumefaciens GV2260 (pBBRacdS, pEAQ-GFP-HT); V3-Q: A. tumefaciens GV2260 (pBBRgabT, pEAQ-GFP-HT); V4-Q: A. tumefaciens GV2260 (pBBRacdSgabT, pEAQ-GFP-HT). 
and V3-G showed almost the same levels (Figure 2C). Therefore, the activities of AcdS and GabT in V4-E and V4-G, were enough to increase the T-DNA transfer frequencies in E. ravennae and S. lycopersicum "Micro-Tom." Additionally, we evaluated the ability of T-DNA transformation with V4 in the Agroinfiltration method. Plasmid pEAQ-GFP-HT was used as a binary vector in Agroinfiltration method. N. benthamiana and S. torvum were inoculated with four strains [(C-Q), (V1-Q), (V3-Q), and (V4$\mathrm{Q})$ ]. The strength of the GFP signal was used as an indicator of the frequency of the T-DNA transfer. In N. benthamiana, V4-Q induced higher GFP expression than the C-Q strain and V1-Q (Figure 2D), but it was the same level as the V3-Q. In S. torvum, the success of the V4-Q strain with the Agroinfiltration treatment was greater than that of the C-Q strain, but the same as that of the V1-Q and V3-Q strains (Figure 2E).

\section{A. tumefaciens With Both AcdS and GabT Activities Resulted in the Enhanced Stable Transformation of Tomato}

V4 was effective at the T-DNA transfer in E. ravennae and $S$. lycopersicum "Micro-Tom" (Figures 2A, C), however this is one step of the stable transformation process. The entire process for Agrobacterium-mediated stable transformation is divided into four steps: i) T-DNA transfer and integration into the plant genome, ii) calli induction, iii) the regeneration of the shoots, and iv) rooting. It was not clear if the V4 affected these other steps. To ascertain this information, the frequency of each process was observed in S. lycopersicum "Micro-Tom," which has a well-established regeneration system for processes (ii) to (iv) (Sun et al., 2006). To characterize each strain, C-G, V1-G, V3-G, and V4-G were used. One-month after inoculation, the calli inductions were observed. All Super-Agrobacterium strains increased the callus inductions compared with the C-G (Figures 3A-D). V1-G and V4-G showed slightly higher calli induction ratios (calli number / segments number) than the V3-G. The C-G, V1-G, V3-G, and V4-G showed calli induction frequencies of $51.5 \pm 0.6,85.2 \pm 8.8,73.8 \pm 2.03$, and $91.8 \pm 3.7 \%$, respectively (Figure 3 E, Table 2 ). Shoot regeneration ratios (shooting number / calli number) were increased with the inoculation of the V3-G and V4-G. V1-G was slightly higher than that of the $\mathrm{C}-\mathrm{G}$. The frequency of the shoot regeneration ratios with the inoculations of C-G, V1-G, V3-G, and V4-G were $49.7 \pm 10.9$, $80.4 \pm 29.2,181.8 \pm 23.4$, and $176.3 \pm 58.9 \%$, respectively (Figure $3 F$, Table 2). The frequencies for rooting from the shoots (rooting number/ shoots number) were similar for all strains (Figure 3G, Table 2). These results suggest that V1-G had positive effects on step (ii) calli induction, V3-G increased step (iii) shooting, and V4-G accelerated both steps (ii) and (iii) in the Agrobacteriummediated stable transformation process. After regenerated diploid shoots (2n) were selected, the exogenous T-DNA was detected by PCR (data not shown) and Southern hybridization analysis (Supplemental Figure 2). The stable transformation frequencies were evaluated with single-copy-number plants, and identification by Southern hybridization analysis. These results imply that all of the lines we obtained were independent and did not contain a cloned plant. The C-G, V1-G, V3-G, and V4-G showed the stable transformation efficiencies of $4.3 \pm 1.9,9.7 \pm 0.4,9.8 \pm 1.6$, and 15.2 $\pm 1.1 \%$, respectively (mean $\pm \mathrm{SD}$ of three repetitions) (Figure $3 \mathrm{H}$ and Table 2). Thus, V4 exhibited approximately 3.6, 1.6, and 1.6 times the stable transformation frequency of C-G, V1-G, and V3-G, respectively. The frequency of regenerated rooting shoot with single copy was same level in all A. tumefaciens strains (Figure 3I).

\section{DISCUSSION}

A. tumefaciens with AcdS and GabT was expected to cause reduced ethylene and GABA content in plants. Indeed, the ethylene levels in the plant tissues during the transformation were reduced by the A. tumefaciens with AcdS activity (Nonaka et al., 2008a; Malambane et al., 2018). On the other hand, significant differences in GABA content during the co-cultivation were not observed between $A$. tumefaciens with GabT activity and the control (data not shown). As A. tumefaciens takes the GABA from the plant into the bacterial cell through a kind of $\mathrm{ABC}$ transporter (Planamente et al., 2010; Planamente et al., 2013), if the GabT activity introduced $A$. tumefaciens, GABA taken into bacterial cell would be degraded. The degradation of GABA occurred only in bacterial cells, and at very localized areas. Therefore, it was difficult to detect the differences of GABA content. ACC deaminase activity and GabT activity in A. tumefaciens were effective at increasing the T-DNA transfer frequency (Nonaka et al., 2008a; Nonaka et al., 2017; Ntui et al., 2010; Hao et al., 2010), but it was not clear which was more effective in Agrobacterium-plant interactions. To ascertain this, the T-DNA transfer abilities of Super-Agrobacterium ver. 1 and ver. 3 were compared in E. ravennae and tomato with the tissue culture and co-cultivation methods. No differences were observed between the strains in E. ravennae and S. lycopersicum "Micro-Tom" (Figures 2A, C). With the Agroinfiltration method, the same tendency was observed in S. torvum (Figure 2E). These results mean that ethylene and GABA influence the T-DNA transfer frequencies at almost the same level in these plant species. On the other hand, in N. benthamiana, Super-Agrobacterium ver. 3 and ver. 4 showed higher level of T-DNA transfer than GV2260 and Super-Agrobacterium ver. 1, but the level of T-DNA transfer was same in ver. 3 and ver. 4 . This showed that in the $N$. benthaminana, AcdS activity did not improve the T-DNA transfer, but GabT activity was effective at increasing the T-DNA transfer. Therefore, in N. benthamiana, GABA is a stronger negative factor than ethylene. From these results, the effect of the Super-Agrobacterium was found to be different, dependent on the plant species, thus the selection of the most suitable strain is important for the successful application of the technology.

Even under conditions where the vir gene is sufficiently expressed, our Super-Agrobacterium strains could further improve T-DNA transfer. In this study, with the tissue culture and co-cultivation methods, $500 \mu \mathrm{M}$ of acetosyringone, which was enough to induce vir gene expression (Nonaka et al., 2008b), was used during co-cultivation. Super-Agrobacterium ver. 1, ver. 3, and ver. 4 further increased the T-DNA transfer frequency, despite the existence of enough vir gene inducers (Figures 2A, C). The additional effects of AcdS and GabT under the acetosyringone indicate that in the T-DNA transfer, the ethylene and GABA affect 


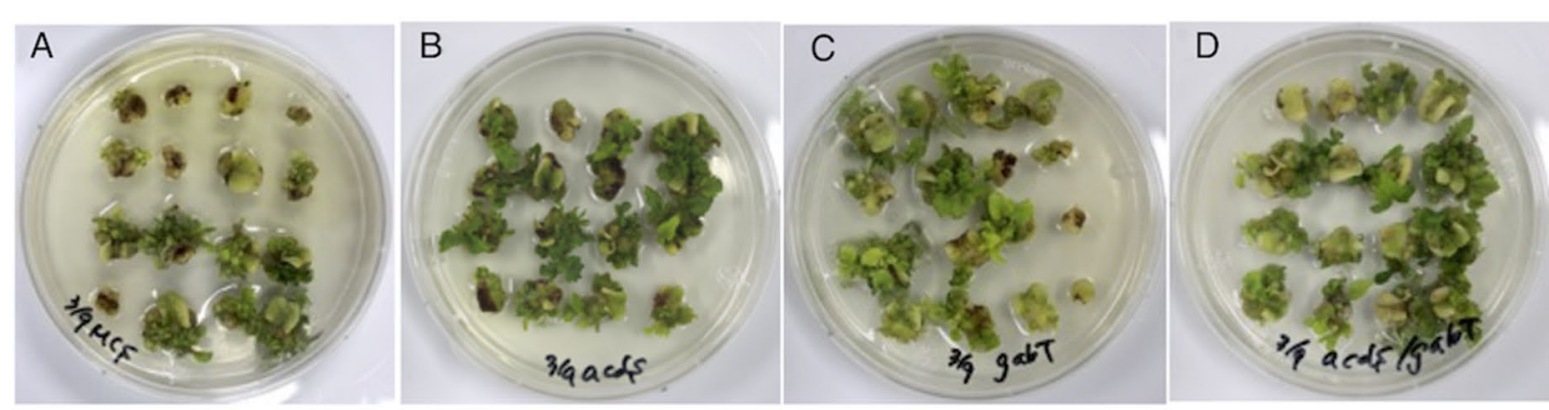

E

F
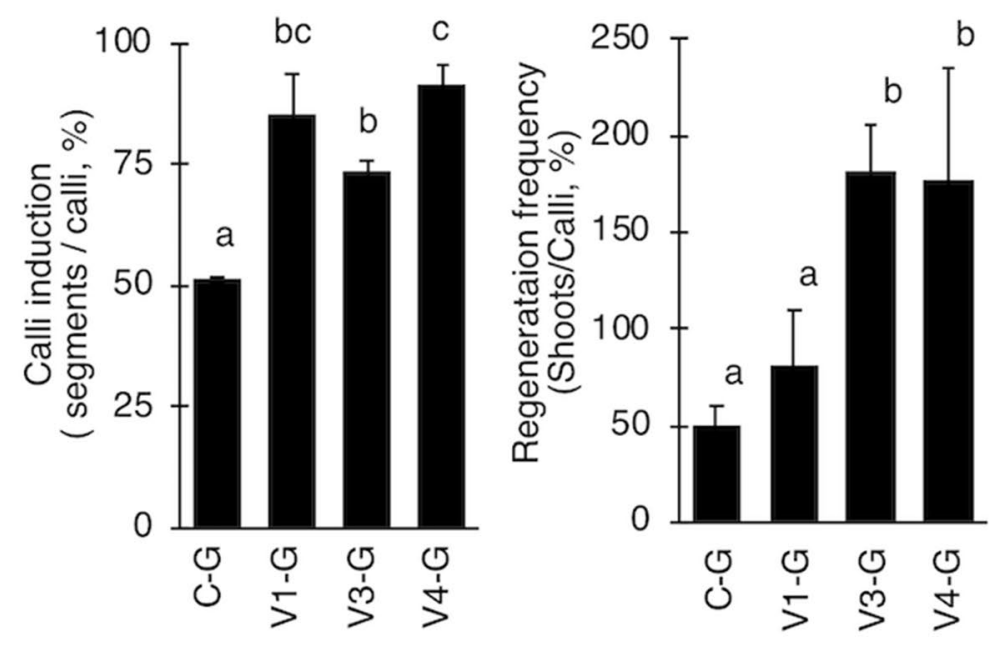

G

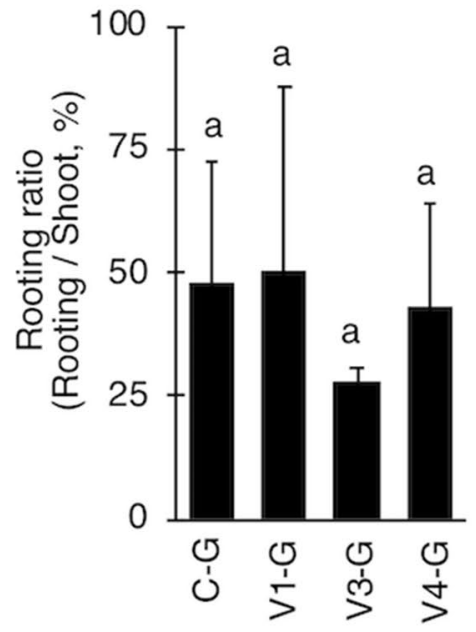

$\mathrm{H}$
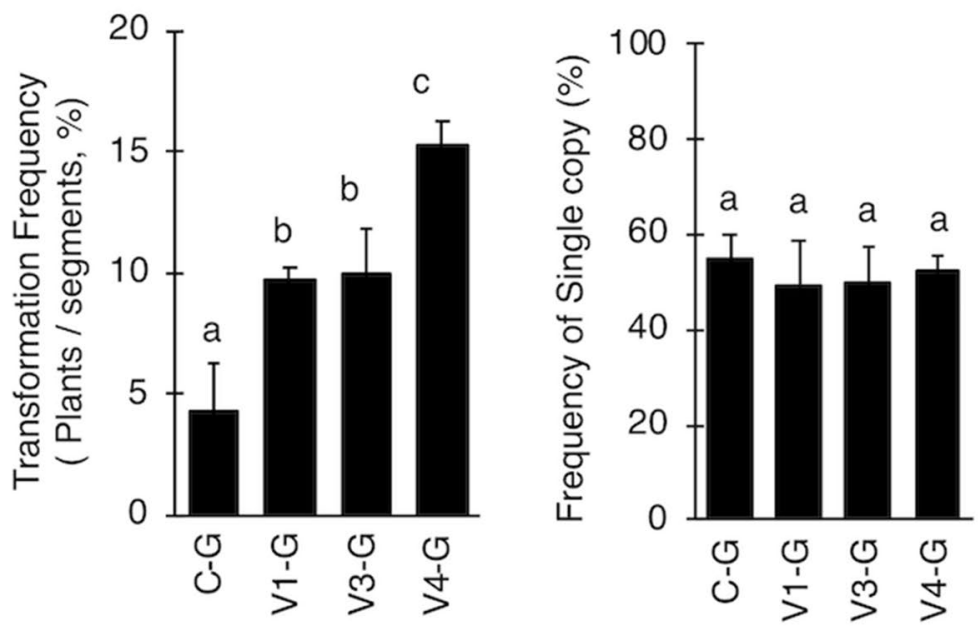

FIGURE 3 | Effect of AcdS and GabT activity on regeneration and stable transformation. Regenerated shoots from "Micro-Tom" calli inoculated with (A) C-G, (B) V1-G, (C) V3-G, and (D) V4-G. (E) Appearance of calli, (F) Frequency of regeneration, (G) Rooting ratio, (H) Frequency of calli regeneration. (I) Frequency of appearence for transgenic tomato plants which have single copy of T-DNA. C-G: A. tumefaciens GV2260 (pBBRMCS1-5, plG121-Hm); V1-G: A. tumefaciens GV2260 (pBBRacdS, plG121-Hm); V3-G: A. tumefaciens GV2260 (pBBRgabT, plG121-Hm); V4-G: A. tumefaciens GV2260 (pBBRacdSgabT, plG121-Hm). Bars represent the standard deviation $(n=3)$. Different characters indicate statistical differences in a one-way ANOVA and the Tukey-Kramer method, multiple comparison method $(P<0.01)$. 
TABLE 2 | Effect of the Super-Agrobacterium ver.1, ver.3, and ver.4 on plant regeneration and transformation of the 'Micro-Tom' cotyledons.

\begin{tabular}{|c|c|c|c|c|c|c|c|c|}
\hline \multirow[b]{2}{*}{$\begin{array}{l}\text { Experiment } \\
\text { repetition }\end{array}$} & \multirow[b]{2}{*}{$\begin{array}{l}\text { Agrobacterium } \\
\text { strain }\end{array}$} & \multicolumn{6}{|c|}{ Numbers of } & \multirow{2}{*}{$\begin{array}{c}\begin{array}{c}\text { Transformation } \\
\text { frequency }\end{array} \\
\begin{array}{c}\text { Inoculated } \\
\text { Segments }\end{array} \\
\text { /Single copy (\%) }\end{array}$} \\
\hline & & Segments & Calli & Shoots & Rooting & Diploid & Single copy & \\
\hline \multirow[t]{4}{*}{$1 \mathrm{st}$} & $C-G$ & 110 & 56 & 26 & 7 & 5 & 3 & 2.7 \\
\hline & V1-G & 125 & 94 & 52 & 47 & 19 & 12 & 9.6 \\
\hline & V3-G & 92 & 80 & 152 & 39 & 14 & 8 & 8.7 \\
\hline & V4-G & 96 & 84 & 163 & 59 & 29 & 14 & 14.6 \\
\hline \multirow[t]{4}{*}{ 2nd } & C-G & 94 & 49 & 20 & 15 & 11 & 6 & 6.4 \\
\hline & V1-G & 88 & 78 & 88 & 15 & 23 & 9 & 10.2 \\
\hline & V3-G & 95 & 72 & 144 & 40 & 22 & 11 & 11.6 \\
\hline & V4-G & 75 & 70 & 157 & 41 & 20 & 11 & 14.7 \\
\hline \multirow[t]{4}{*}{ 3rd } & C-G & 82 & 42 & 26 & 11 & 6 & 3 & 3.7 \\
\hline & V1-G & 85 & 78 & 57 & 25 & 16 & 8 & 9.4 \\
\hline & V3-G & 88 & 65 & 101 & 31 & 16 & 8 & 9.1 \\
\hline & V4-G & 91 & 86 & 95 & 63 & 28 & 15 & 16.5 \\
\hline
\end{tabular}

Each column "Segments," "Calli," "Shoots," "Rooting," "Diploid," and "Single copy" indicated the number of occurrences. "Segments" means the number of segments used for inoculation of A. tumefaciens. "Calli," "Shoots," and "Rooting" showed the number of regenerate calli, shoot, and rooting. "Diploid" was the number rooting shoots that were diploid, detected by the ploidy analyzer. "Single copy" means the number of diploid rooting shoots with single copy of T-DNA, identified by Southern blot analysis. Transformation frequency was calculated as follows: the total number of transgenic plants with diploid and single copy was divided by the number of explants inoculated and then multiplied by 100 . Only one plant regenerated per cotyledon explant was considered to calculate transformation efficiency. Three replications were done for this experiment.

different from the level of vir gene inducer. Previous studies have demonstrated that GABA was independent of vir gene expression (Chevrot et al., 2006; Haudecoeur et al., 2009). Thus, the inhibition of GABA further increased the transformation. On the other hand, research has shown that the ethylene target points are involved with vir gene expression, and the ethylene perceiving plant would reduce vir gene inducers or release antagonists of the vir gene inducers (Nonaka et al., 2008b). If the target point of the ethylene was the reduction of the vir gene inducer, the effect of the SuperAgrobacterium ver. 1 would be masked by acetosyringone. In fact, our results showed that the Super-Agrobacterium ver. 1 increased the transformation frequency up to 3.2 and 2.8 times in E. ravennae and $S$. lycopersicum, respectively, even with the application of the vir gene inducers. Therefore, these results suggest that the target point of ethylene is not the reduction of vir gene inducers, but the suppression of the antagonists.

In Super-Agrobacterium ver. 4, the enzymatic activity was one third of the Super-Agrobacterium ver. 1 and ver. 3, but it was effective in E. ravennae and S. lycopersicum "Micro-Tom" (Figures 2A, C). The amount of AcdS protein in the Super-Agrobacterium ver. 4 was one third of that found in Super-Agrobacterium ver. 1 (Supplemental Figure 3). Expressing multiple genes using the same promoter may reduce the expression levels of each gene. In this study, we used the lac promoter to drive both the acdS and gabT genes. If stronger promoters were used, the expression levels would be increased. Previous research compared the vir gene promoters ( $\operatorname{vir} B, \operatorname{vir} C$, and $\operatorname{vir} D$ ) with the lac promoter activities; the vir gene promoters were found to show higher promoter activities than the lac promoter (Someya et al., 2013). Therefore, using these promoters would be effective to increase acd $S$ and gabT expression in the Super-Agrobacterium ver. 4. Indeed, replacement of the promoter increased the acdS gene expression and the activity in A. tumefaciens, resulting in increased T-DNA transformation frequencies (Super-Agrobacterium ver. 2) (Someya et al., 2013). Therefore, replacing promoters would increase the transient transformations in S. torvum via the agroinfiltration method.

In this study, the stable transformation frequency was $15.2 \pm$ $1.1 \%$. This value was calculated as the ratio between independently transformed plants with diploid and single copy number in soil (checked by a ploidy analyzer and Southern blot analysis) and the total number of explants infected with A. tumefaciens. Previous studies have reported transformation frequencies that differ from ours (Sun et al., 2006; Khoudi et al., 2009; Khuong et al., 2013; Chetty et al., 2013). The transformation frequency might depend on the bacterial strain, binary vector and the selection method. In our study, the transformation frequency was calculated using regenerated rooting shoot with diploid and a single copy per inoculated segment. In contrast, most previous studies calculated this frequency from the PCR-positive tomatoes (Sun et al., 2006; Khoudi et al., 2009; Khuong et al., 2013; Chetty et al., 2013). Therefore, it would be difficult to compare between our and previous results. To create a transgenic plant, it is important to avoid somaclonal variation and multiple copies, which our method did.

The process of Agrobacterium-mediated stable transformation contains four steps: i) the T-DNA transfer into plant cells and integration into the host genome, ii) callus induction, iii) the regeneration of shoots, and iv) rooting. The activity of AcdS and GabT increased step (i) (Figures 2A, C). In the rooting step, there were no significant differences detected between them. Other steps showed different responses to AcdS and/or GabT activity (Figure 3 and Table 2). The AcdS activity showed higher callus induction frequencies than the GabT activity, whereas the GabT activity induced higher shoot regeneration ratios than the AcdS. The browning callus appearance was suppressed by A. tumefaciens with AcdS (Figures 3A-D), as the ethylene induced hypersensitive responses and programmed cell death 
(Wang et al., 2017); infection of A. tumefaciens with AcdS (Super-Agrobacterium ver. 1 or ver. 4 ) with the ability to remove ethylene, suppressed the browning phenomena. Although the function of GABA in plants needs to be clarified, there have been several studies regarding the functions of GABA as a signaling compound in plant growth and development. The increased endogenous concentrations of GABA seem to be the reason for impaired cell elongation in the Arabidopsis thaliana mutants, pop2, and her1, and the corresponding phenotypes (Renault et al., 2011). Infection of A. tumefaciens with GabT activity locally decreased GABA content in the plant calli and maintained higher shoot regeneration frequencies. Since both activities have different effective points in the transformation process, Super-Agrobacterium ver. 4. with AcdS and GabT activity at the same time, enhanced the stable transformation frequency approximately 3.6 times, compared with that of the original GV2260 strain.

We succeeded in producing an A. tumefaciens strain with improved potential for transformation by imbuing it with the ability to remove ethylene and GABA, which are negative factors in the Agrobacterium-plant interactions. A. tumefaciens with AcdS and GabT increased the T-DNA tranfer and stable transformation frequency. Especially in tomato, this newly bred bacterium (Super-Agrobacterium ver. 4) enables us to decrease the number of cotyledons used for transformation and allows us to reduce $72 \%$ of the time and labor required for transformation. Moreover, because our system was the plasmid with acdS and gabT gene, it is used in combination with other strains, such as the EHA105, EHA101, LBA4404, MP90, and AGL1. Based on this, we conclude that this new system is a useful tool for plant genetic engineering. On the other hand, the frequency is still not enough depending on the plant species and cultivars (Figures 3E, F). Therefore, the additional effort should have been required to adapt Agrobacterium-mediated transformation for a wide variety of plants. Other negative factors in Agrobacteriumplant interactions, aside from ethylene and GABA, have been reported by previous studies (Liu and Nester, 2006; Yuan et al., 2007; Yuan et al., 2008; Anand et al., 2008). Therefore, to expand plant spices and cultivars adapting Agrobacterium-mediated transformation, multiply suppress of these negative factors would be also effective.

\section{DATA AVAILABILITY STATEMENT}

All datasets GENERATED for this study are included in the manuscript/Supplementary Files.

\section{AUTHOR CONTRIBUTIONS}

SN designed the experiments, analyzed the data, and wrote the manuscript. TS constructed the plasmid pBBRacdSgabT and did the western blot analysis. YK performed the experiments about Agroinfiltration. HE and KN critically revised and approved the manuscript for publication.

\section{FUNDING}

This research was supported by grants from the New Energy and Industrial Technology Development Organization (NEDO) to HE and from JSPS KAKENHI (Grant Numbers JP24780001 and JP19K05964) to SN. Cooperative Research Grant from Plant Transgenic Design Initiative (PTraD), Gene Research Center in Tsukuba Innovation Plant Research Center (T-PIRC), University of Tsukuba, Japan supported this research.

\section{ACKNOWLEDGMENTS}

We appreciate the help of Prof. Mii (Chiba University, Japan) for kindly providing the E. ravennae calli. We also thank Prof. Nakamura (Chiba University, Japan) and Prof. Mitsui (Tohoku University, Japan) for the gift of the $\mathrm{pEKH}_{2}$ plasmid and pBBR1MCS-5, respectively. We would like to thank Editage (www.editage.jp) for English language editing.

\section{SUPPLEMENTARY MATERIAL}

The Supplementary Material for this article can be found online at: https://www.frontiersin.org/articles/10.3389/fpls.2019.01204/ full\#supplementary-material

SUPPLEMENTAL FIGURE 1 | Map of binary vectors. (A) Map of $\mathrm{pEK \textrm {H } _ { 2 } -}$ nosPNPTII-ubiPGUS-35SPHPT. NosP; Nopalin synthesis gene promoter, UbiP ubiquitin gene promoter from rice, NosT; Nopalin synthesis gene terminator, nptI/; neomycin phosphotransferase gene, uidA; beta-glucuronidase gene, hptIl; hygromycin phosphotransferase gene, OriV; replication origin V (IncPa, plasmid RK2 from E. coli, GeneBank accession \#J01780), KanR; Kanamycin resistance gene. RB; Right border sequence, LB; Left border sequence. (B) Map of plG121-Hm. NosP; Nopalin synthesis gene promoter, CaMV 35S P; Cauliflower mosaic virus 35S promoter, NosT; Nopalin synthesis gene terminator, nptIl; neomycin phosphotransferase gene, uidA; beta-glucuronidase gene, hptll; hygromycin phosphotransferase gene, OriV; replication origin V (IncPa, plasmid RK2 from E. coli, GeneBank accession \#J01780), KanR; Kanamycin resistance gene, RB; Right border sequence, LB; Left border sequence. (C) Map of pEAQGFP-HT. CaMV 35S P; Cauliflower mosaic virus 35S promoter, NosT; Nopalin synthesis gene terminator, GFP; green fluorescence gene, RB; Right border sequence, LB; Left border sequence.

SUPPLEMENTAL FIGURE 2 | Map of the pIG121-Hm vector and the southern blot analysis of the $\mathrm{T}_{0}$ generation. (A) Present the maps of the T-DNA region in the plG121-Hm expression vectors used for the stable transformation. Red bars represent the position of probes used in the southern blot analysis. Hindlll indicates the restriction enzyme sites that were used in the southern hybridization. NPTII probes were used in. (B) Southern blot analysis of the $T_{0}$ generation. Red numbers indicate the transgenic lines with single copy. C-G: A. tumefaciens GV2260 (pBBRMCS1-5, plG121-Hm); V1-G: A. tumefaciens GV2260 (pBBRacdS, plG121-Hm); V3-G: A. tumefaciens GV2260 (pBBRgabT, plG121-Hm); V4-G: A. tumefaciens GV2260 (pBBRacdSgabT, pIG121-Hm).

SUPPLEMENTAL FIGURE 3 | Western blot analysis of ACC deaminase expression in A. tumefaciens strains using the cell lysate at the 'Early stage' (O.D.600 0.7). ACC deaminase was probed with an anti-ACC deaminase antibody. Coomassie Brilliant Blue staining (bottom panel) is shown as an internal control. C-G: A. tumefaciens GV2260 (pBBRMCS1-5, plG121-Hm); V1-G: A. tumefaciens GV2260 (pBBRacdS, plG121-Hm); V3-G: A. tumefaciens GV2260 (pBBRgabT, plG121-Hm); V4-G: A. tumefaciens GV2260 (pBBRacdSgabT, plG121-Hm). 


\section{REFERENCES}

Akihiro, T., Koike, S., Tani, R., Tominaga, T., Watanabe, S., Iijima, Y., et al. (2008). Biochemical mechanism on GABA accumulation during fruit development in tomato. Plant Cell Physiol. 49 (9), 1378-1389. doi: 10.1093/pcp/pcn113

Anand, A., Uppalapati, S. R., Ryu, C. M., Allen, S. N., Kang, L., Tang, Y., et al. (2008). Salicylic acid and systemic acquired resistance play a role in attenuating crown gall disease caused by Agrobacterium tumefaciens. Plant Physiol. 146 (2), 703-175. doi: 10.1104/pp.107.111302

Bevan, M. (1984). Binary Agrobacterium vectors for plant transformation. Nucleic Acids Res. 12 (22), 8711-8721. doi: 10.1093/nar/12.22.8711

Bradford, M. M. (1976). A rapid and sensitive method for the quantitation of microgram quantities of protein utilizing the principle of protein-dye binding. Anal. Biochem. 72, 248-254. doi: 10.1016/0003-2697(76)90527-3

Cangelosi, G. A., Ankenbauer, R. G., and Nester, E. W. (1990). Sugars induce the Agrobacterium virulence genes through a periplasmic binding protein and a transmembrane signal protein. Proc. Natl. Acad. Sci. U. S. A. 87 (17), 67086712. doi: $10.1073 /$ pnas.87.17.6708

Chetty, V. J., Ceballos, N., Garcia, D., Narváez-Vásquez, J., Lopez, W., and OrozcoCárdenas, M. L. (2013). Evaluation of four Agrobacterium tumefaciens strains for the genetic transformation of tomato (Solanum lycopersicum L.) cultivar Micro-Tom. Plant Cell Rep. 32 (2), 239-247. doi: 10.1007/s00299-012-1358-1

Chevrot, R., Rosen, R., Haudecoeur, E., Cirou, A., Shelp, B. J., Ron, E., et al. (2006). GABA controls the level of quorum-sensing signal in Agrobacterium tumefaciens. Proc. Natl. Acad. Sci. U. S. A. 103 (19), 7460-7464. doi: 10.1073/ pnas. 0600313103

Davis, M. E., Miller, A. R., and Lineberger, R. D. (1992). Studies on the effects of ethylene on transformation of tomato cotyledons (Lycopersicon esculentum Mill.) by Agrobacterium tumefaciens. J. Plant Physiol. 139 (3), 309-312. doi: 10.1016/S0176-1617(11)80343-3

Deblaere, R., Bytebier, B., De Greve, H., Deboeck, F., Schell, J., Van Montagu, M., et al. (1985). Efficient octopine Ti plasmid-derived vectors for Agrobacteriummediated gene transfer to plants. Nucleic Acids Res. 13 (13), 4777-4788. doi: 10.1093/nar/13.13.4777

Elliott, K. A. C., and Hobbiger, F. (1959). Gamma aminobutyric acid: circulatory and respiratory effects in different species; re-investigation of the anti-strychnine action in mice. J. Physiol. 146, 70-84. doi: 10.1113/jphysiol.1959.sp006178

Ezura, H., Yuhashi, K. I., Yasuta, T., and Minamisawa, K. (2000). Effect of ethylene on Agrobacterium tumefaciens-mediated gene transfer to melon. Plant Breed. 119 (1), 75-79. doi: 10.1046/j.1439-0523.2000.00438.x

Forlani, G., Bertazzini, M., and Giberti, S. (2014). Differential accumulation of $\gamma$-aminobutyric acid in elicited cells of two rice cultivars showing contrasting sensitivity to the blast pathogen. Plant Biol. 16 (6), 1127-1132. doi: 10.1111/ plb. 12165

Guo, M., Ye, J., Gao, D., Xu, N., and Yang, J. (2019). Agrobacterium-mediated horizontal gene transfer: Mechanism, biotechnological application, potential risk and forestalling strategy. Biotechnol Adv. 37 (1), 259-270. doi: 10.1016/j. biotechadv.2018.12.008

Han, J. S., Kim, C. K., Park, S. H., Hirschi, K. D., and Mok, I. (2005). Agrobacteriummediated transformation of bottle gourd (Lagenaria siceraria Standl.). Plant Cell Rep. 23 (10-11), 692-698. doi: 10.1007/s00299-004-0874-z

Hao, Y., Charles, T. C., and Glick, B. R. (2010). ACC deaminase increases the Agrobacterium tumefaciens-mediated transformation frequency of commercial canola cultivars. FEMS Microbiol. Lett. 307 (2), 185-190. doi: 10.1111/j.1574-6968.2010.01977.x

Haudecoeur, E., Planamente, S., Cirou, A., Tannières, M., Shelp, B. J., Moréra, S., et al. (2009). Proline antagonizes GABA-induced quenching of quorumsensing in Agrobacterium tumefaciens. Proc. Natl. Acad. Sci. U. S. A. 106 (34), 14587-14592. doi: $10.1073 /$ pnas. 0808005106

He, F., Nair, G. R., Soto, C. S., Chang, Y., Hsu, L., Ronzone, E., et al. (2009). Molecular basis of ChvE function in sugar binding, sugar utilization, and virulence in Agrobacterium tumefaciens. J. Bacteriol. 191 (18), 5802-5813. doi: 10.1128/JB.00451-09

Hiei, Y., Ohta, S., Komari, T., and Kumashiro, T. (1994). Efficient transformation of rice (Oryza sativa L.) mediated by Agrobacterium and sequence analysis of the boundaries of the T-DNA. Plant J. 6 (2), 271-282. doi: 10.1046/j.1365-313X.1994.6020271.x
Hoekema, A., Hirsch, P. R., Hooykaas, P. J. J., and Schilperoort, R. A. (1983). A binary plant vector strategy based on separation of vir- and T-region of the Agrobacterium tumefaciens Ti-plasmid. Nature 303 (5913), 179-180. doi: 10.1038/303179a0

Honma, S., and Shimomura, T. (1978). Metabolism of 1-aminocyclopropane-1carboxylic acid. Agric. Biol. Chem. 42 (10), 1825-1831. doi: 10.1080/00021369. 1978.10863261

Hoshikawa, K., Fujita, S., Renhu, N., Ezura, K., Yamamoto, T., Nonaka, S., et al. (2019). Efficient transient protein expression in tomato cultivars and wild species using agroinfiltration-mediated high expression system. Plant Cell Rep. 38 (1), 75-84. doi: 10.1007/s00299-018-2350-1

Hoshikawa, K., Ishihara, G., Takahashi, H., and Nakamura, I. (2012). Enhanced resistance to gray mold (Botrytis cinerea) in transgenic potato plants expressing thionin genes isolated from Brassicaceae species. Plant Biotechnol. 29, 87-93. doi: $10.5511 /$ plantbiotechnology.12.0125a

Hu, X., Zhao, J., DeGrado, W. F., and Binns, A. N. (2013). Agrobacterium tumefaciens recognizes its host environment using $C h v E$ to bind diverse plant sugars as virulence signals. Proc. Natl. Acad. Sci. U. S. A. 110 (2), 678-683. doi: 10.1073/pnas. 1215033110

Ishida, Y., Saito, H., Ohta, S., Hiei, Y., Komari, T., and Kumashiro, T. (1996). High efficiency transformation of maize (Zea mays L.) mediated by Agrobacterium tumefaciens. Nat. Biotechnol. 14 (6), 745-750. doi: 10.1038/nbt0696-745

Kado, C. I. (2014). Historical account on gaining insights on the mechanism of crown gall tumorigenesis induced by Agrobacterium tumefaciens. Front Microbiol. 5, 340. doi: 10.3389/fmicb.2014.00340

Khoudi, H., Nouri-Khemakhem, A., Gouiaa, S., and Masmoudi, K. (2009). Optimization of regeneration and transformation parameters in tomato and improvement of its salinity and drought tolerance. Afr. J. Biotechnol. 8, 60686076. doi: 10.5897/AJB09.057

Khuong, T. T., Crété, P., Robaglia, C., and Caffarri, S. (2013). Optimisation of tomato Micro-tom regeneration and selection on glufosinate/Basta and dependency of gene silencing on transgene copy number. Plant Cell Rep. 32 (9), 1441-1454. doi: 10.1007/s00299-013-1456-8

Knoch, E., Sugawara, S., Mori, T., Poulsen, C., Fukushima, A., Harholt, J., et al. (2019). Third DWF1 paralog in Solanaceae, sterol $\Delta 24$-isomerase, branches withanolide biosynthesis from the general phytosterol pathway. Proc. Natl. Acad. Sci. U. S. A. 115 (34), E8096-E8103. doi: 10.1073/pnas.1807482115

Komari, T. (1990). Transformation of cultured cells of Chenopodium quinoa by binary vectors that carry a fragment of DNA from the virulence region of pTiBo542. Plant Cell Rep. 9 (6), 303-306. doi: 10.1007/BF00232856

Komari, T., Takakura, Y., Ueki, J., Kato, N., Ishida, Y., and Hiei, Y. (2006). Binary vectors and super-binary vectors. Methods Mol. Biol. 343, 15-41. doi: 10.1385/1-59745-130-4:15

Kovach, M. E., Elzer, P. H., Hill, D. S., Robertson, G. T., Farris, M. A., Roop, R. M., 2nd, et al. (1995). Four new derivatives of the broad-host-range cloning vector pBBR1MCS, carrying different antibiotic-resistance cassettes. Gene. 166 (1), 175-176. doi: 10.1016/0378-1119(95)00584-1

Liu, P., and Nester, E. W. (2006). Indoleacetic acid, a product of transferred DNA, inhibits vir gene expression and growth of Agrobacterium tumefaciens C58. Proc. Natl. Acad. Sci. U. S. A. 103 (12), 4658-4662. doi: 10.1073/pnas.0600366103

Malambane, G., Nonaka, S., Shiba, H., Ezura, H., Tsujimoto, H., and Akashi, K. (2018). Comparative effects of ethylene inhibitors on Agrobacterium-mediated transformation of drought-tolerant wild watermelon. Biosci Biotechnol Biochem. 82 (3), 433-441. doi: 10.1080/09168451.2018.1431516

Murashige, T., and Skoog, F. (1962). A revised medium for rapid growth and bio assays with tobacco tissue cultures. Physiol. Plant. 15, 473-497. doi: 10.1111/ j.1399-3054.1962.tb08052.x

Nonaka, S., and Ezura, H. (2014). Plant-Agrobacterium interaction mediated by ethylene and super-Agrobacterium conferring efficient gene transfer. Front. Plant Sci. 5, 681. doi: 10.3389/fpls.2014.00681

Nonaka, S., Someya, T., Zhou, S., Takayama, M., Nakamura, K., and Ezura, H. (2017). An Agrobacterium tumefaciens strain with gamma-aminobutyric acid transaminase activity shows an enhanced genetic transformation ability in plants. Sci. Rep. 7, 42649. doi: 10.1038/srep42649

Nonaka, S., Sugawara, M., Minamisawa, K., Yuhashi, K., and Ezura, H. (2008a). 1-Aminocyclopropane-1-carboxylate deaminase enhances Agrobacterium tumefaciens-mediated gene transfer into plant cells. Appl. Environ. Microbiol. 74 (8), 2526-2528. doi: 10.1128/AEM.02253-07 
Nonaka, S., Yuhashi, K., Takada, K., Sugaware, M., Minamisawa, K., and Ezura, H. (2008b). Ethylene production in plants during transformation suppresses vir gene expression in Agrobacterium tumefaciens. New Phytol. 178 (3), 647-656. doi: $10.1111 / j .1469-8137.2008 .02400 . x$

Ntui, V. O., Khan, R. S., Chin, D. P., Nakamura, I., and Mii, M. (2010). An efficient Agrobacterium tumefaciens-mediated genetic transformation of "Egusi" melon (Colocynthis citrullus L.). Plant Cell Tiss. Organ. Cult. 103, 15-22. doi: 10.1007/ s11240-010-9748-y

Ohta, S., Mita, S., Hattori, T., and Nakamura, K. (1990). Construction and expression in tobacco of a $\beta$-glucuronidase (GUS) reporter gene containing an intron within the coding sequence. Plant Cell Physiol. 31, 805-813. doi: 10.1093/oxfordjournals.pcp.a077982

Park, D. H., Mirabella, R., Bronstein, P. A., Preston, G. M., Haring, M. A., Lim, C. K., et al. (2010). Mutations in $\gamma$-aminobutyric acid (GABA) transaminase genes in plants or Pseudomonas syringae reduce bacterial virulence. Plant J. 64 (2), 318-330. doi: 10.1111/j.1365-313X.2010.04327.x

Planamente, S., Moréra, S., and Faure, D. (2013). In planta fitness-cost of the Atu4232-regulon encoding for a selective GABA-binding sensor in Agrobacterium. Commun Integr Biol. 6 (3), e23692. doi: 10.4161/cib.23692

Planamente, S., Vigouroux, A., Mondy, S., Nicaise, M., Faure, D., and Moréra, S. (2010). A conserved mechanism of GABA binding and antagonism is revealed by structure-function analysis of the periplasmic binding protein Atu2422 in Agrobacterium tumefaciens. J Biol Chem. 285 (39), 30294-30303. doi: 10.1074/ jbc.M110.140715

Renault, H., El Amrani, A., Palanivelu, R., Updegraff, E. P., Yu, A., Renou, J. P., et al., et al. (2011). GABA accumulation causes cell elongation defects and a decrease in expression of genes encoding secreted and cell wall-related proteins in Arabidopsis thaliana. Plant Cell Physiol. 52 (5), 894-908. doi: 10.1093/pcp/ pcr041

Sainsbury, F., Thuenemann, E. C., and Lomonossoff, G. P. (2009). pEAQ: versatile expression vectors for easy and quick transient expression of heterologous proteins in plants. Plant Biotechnol. J. 7 (7), 682-693. doi: 10.1111/j.1467-7652.2009.00434.x

Sheehy, R. E., Honma, M., Yamada, M., Sasaki, T., Martineau, B., and Hiatt, W. R. (1991). Isolation, sequence, and expression in Escherichia coli of the Pseudomonas sp. strain ACP gene encoding 1-aminocyclopropane1-carboxylate deaminase. J Bacteriol. 173 (17), 5260-5265. doi: 10.1128/ jb.173.17.5260-5265.1991

Shelp, B. J., Bozzo, G. G., Trobacher, C. P., Zarei, A., Deyman, K. L., and Brikis, C. J. (2012). Hypothesis/review: contribution of putrescine to 4-aminobutyrate (GABA) production in response to abiotic stress. Plant Sci. 193-194, 130-135. doi: 10.1016/j.plantsci.2012.06.001

Someya, T., Nonaka, S., Nakamura, K., and Ezura, H. (2013). Increased 1-aminocyclopropane-1-carboxylate deaminase activity enhances Agrobacterium tumefaciens-mediated gene delivery into plant cells. Microbiol. Open. 2 (5), 873880. doi: $10.1002 / \mathrm{mbo} 3.123$

Stachel, S. E., Messens, E., Van Montagu, M., and Zambryski, P. (1985). Identification of the signal molecules produced by wounded plant cells that activate T-DNA transfer in Agrobacterium tumefaciens. Nature 318 (6047), 624-629. doi: 10.1038/318624a0

Stachel, S. E., Nester, E. W., and Zambryski, P. C. (1986). A plant cell factor induces Agrobacterium tumefaciens vir gene expression. Proc. Natl. Acad. Sci. U. S. A. 83 (2), 379-383. doi: 10.1073/pnas.83.2.379

Sun, H. J., Uchii, S., Watanabe, S., and Ezura, H. (2006). A highly efficient transformation protocol for Micro-Tom, a model cultivar for tomato functional genomics. Plant Cell Physiol. 47 (3), 426-431. doi: 10.1093/pcp/pci251
Takahashi, H., Sumi, M., and Koshino, F. (1961). Effect of gamma-aminobutyric acid (GABA) on normotensive or hypertensive rats and men. Jpn. J. Physiol. 11, 89-95. doi: 10.2170/jjphysiol.11.89

Takahashi, H., Tiba, M., Iino, M., and Takayasu, T. (1995). The effect of $\gamma$-aminobutyric acid on blood pressure. Jpn. J. Physiol. 5, 334-341. doi: 10.2170/jjphysiol.5.334

Vaghchhipawala, Z., Radke, S., Nagy, E., Russell, M. L., Johnson, S., Gelvin, S. B., et al. (2018). RepB C-terminus mutation of a pRi-repABC binary vector affects plasmid copy number in Agrobacterium and transgene copy number in plants. PLoS One. 13 (11), e0200972. doi: 10.1371/journal.pone.0200972.

van der Fits, L., Deakin, E. A., Hoge, J. H. C., and Memelink, J. (2000). The ternary transformation system: constitutive virG on a compatible plasmid dramatically increases Agrobacterium-mediated plant transformation. Plant Mol. Biol. 43 (4), 495-502. doi: 10.1023/A:1006440221718

Velásquez, A. C., Chakravarthy, S., and Martin, G. B. (2009). Virus-induced gene silencing (VIGS) in Nicotiana benthamiana and tomato. J Vis Exp. 10, 1292. doi: $10.3791 / 1292$

Wang, H., Lin, J., Chang, Y., and Jiang, C. Z. (2017). Comparative transcriptomic analysis reveals that ethylene/ $\mathrm{H} 2 \mathrm{O} 2$-mediated hypersensitive response and programmed cell death determine the compatible interaction of sand pear and Alternaria alternata. Front. Plant Sci. 8, 195. doi: 10.3389/ fpls.2017.00195

Wood, D. W., Setubal, J. C., Kaul, R., Monks, D. E., Kitajima, J. P., Okura, V. K., et al. (2001). The genome of the natural genetic engineer Agrobacterium tumefaciens C58. Science. 294 (5550), 2317-2323. doi: 10.1126/science.1066804

Ye, X., Williams, E. J., Shen, J., Johnson, S., Lowe, B., Radke, S., et al. (2011). Enhanced production of single copy backbone-free transgenic plants in multiple crop species using binary vectors with a pRi replication origin in Agrobacterium tumefaciens. Transgenic Res. 20 (4), 773-786. doi: 10.1007/ s11248-010-9458-6

Yuan, Z. C., Edlind, M. P., Liu, P., Saenkham, P., Banta, L. M., Wise, A. A., et al. (2007). The plant signal salicylic acid shuts down expression of the vir regulon and activates quormone-quenching genes in Agrobacterium. Proc. Natl. Acad. Sci. U. S. A. 104 (28), 11790-11795.

Yuan, Z. C., Haudecoeur, E., Faure, D., Kerr, K. F., and Nester, E. W. (2008). Comparative transcriptome analysis of Agrobacterium tumefaciens in response to plant signal salicylic acid, indole-3-acetic acid and gamma-amino butyric acid reveals signalling cross-talk and Agrobacterium-plant co-evolution. Cell Microbiol. 10 (11), 2339-2354. doi: 10.1111/j.1462-5822.2008.01215.x

Zambryski, P., Joos, H., Genetello, C., Leemans, J., Van Montagu, M., and Schell, J. (1983). Ti plasmid vector for the introduction of DNA into plant cells without alteration of their normal regeneration capacity. EMBO J. 2 (12), 2143-2150. doi: 10.1002/j.1460-2075.1983.tb01715.x

Conflict of Interest: The authors declare that the research was conducted in the absence of any commercial or financial relationships that could be construed as a potential conflict of interest.

Copyright (c) 2019 Nonaka, Someya, Kadota, Nakamura and Ezura. This is an openaccess article distributed under the terms of the Creative Commons Attribution License (CC BY). The use, distribution or reproduction in other forums is permitted, provided the original author(s) and the copyright owner(s) are credited and that the original publication in this journal is cited, in accordance with accepted academic practice. No use, distribution or reproduction is permitted which does not comply with these terms. 